\title{
Micropropagação do híbrido PExSC-52 e da cultivar Smooth Cayenne de abacaxizeiro
}

\author{
Sarah Brandão Santa Cruz Barboza( ${ }^{(1)}$, Linda Styer Caldas ${ }^{(2)}$ e Luiz Augusto Copati Souza ${ }^{(3)}$
}

\begin{abstract}
(1)Empresa de Desenvolvimento Agropecuário/Embrapa Tabuleiros Costeiros, Caixa Postal 44, CEP 44001-970 Aracaju, SE. E-mail: sarah@cpatc.embrapa.br (2)Universidade de Brasília, Caixa Postal 04457, CEP 70919-970, Brasília, DF. E-mail: Iscaldas@unb.br (3)QE 19, conjunto L, casa 11, Guará II, CEP 71050-123 Brasília, DF. E-mail: luizcopati@uol.com.br
\end{abstract}

Resumo - A produção de mudas de abacaxizeiro de qualidade, em curto período, exige a otimização de protocolos de multiplicação in vitro. O objetivo deste trabalho foi testar cinco combinações de fitorreguladores, baseadas em resultados de pesquisa publicados com micropropagação de abacaxizeiro, na multiplicação in vitro do híbrido PExSC-52 e da cultivar Smooth Cayenne. Gemas axilares foram cultivadas em meio MS contendo benzilaminopurina (BAP) $2 \mathrm{mg} / \mathrm{L}$; BAP $2 \mathrm{mg} / \mathrm{L}$ + ácido naftaleno acético (ANA) $2 \mathrm{mg} / \mathrm{L}$; cinetina (CIN) $2 \mathrm{mg} / \mathrm{L}$; CIN $2 \mathrm{mg} / \mathrm{L}$ + ANA $2 \mathrm{mg} / \mathrm{Le}$ CIN $5 \mathrm{mg} / \mathrm{L}$ + ácido indolacético (AIA) $5 \mathrm{mg} / \mathrm{L}$. No híbrido, BAP $2 \mathrm{mg} / \mathrm{L}$ proporcionou maior proliferação de brotos por explante por subcultura e taxa de multiplicação crescente até a quarta subcultura. BAP $2 \mathrm{mg} / \mathrm{L}+$ ANA $2 \mathrm{mg} / \mathrm{L}$ multiplicou melhor a cv. Smooth Cayenne. Quando se utilizou CIN praticamente não ocorreu proliferação de brotos. Brotações do híbrido provenientes da quarta subcultura em presença de BAP $2 \mathrm{mg} / \mathrm{L}$ e BAP $2 \mathrm{mg} / \mathrm{L}$ + ANA $2 \mathrm{mg} / \mathrm{L}$ foram enraizados em meio MS contendo: ANA $1 \mathrm{mg} / \mathrm{L}$; ANA $1 \mathrm{mg} / \mathrm{L}+\mathrm{CIN} 2 \mathrm{mg} / \mathrm{L} ;$ ANA 0,5 mg/L + CIN $2 \mathrm{mg} / \mathrm{L} ; \mathrm{CIN} 2 \mathrm{mg} / \mathrm{L}$ e sem fitorregulador. Brotos multiplicados em BAP enraizaram melhor que aqueles multiplicados em BAP + ANA.

Termos para indexação: Ananas comosus, cultivo in vitro, taxa de multiplicação, reguladores de crescimento.

\section{Micropropagation of pineapple hybrid PExSC-52 and cultivar Smooth Cayenne}

\begin{abstract}
Five hormonal combinations were evaluated on the in vitro multiplication of pineapple hybrid PExSC-52 and cultivar Smooth Cayenne. After sterilization, axillary buds were inoculated in medium MS with benzilaminopurine (BAP) $2 \mathrm{mg} / \mathrm{L}, \mathrm{BAP} 2 \mathrm{mg} / \mathrm{L}$ + naphthaleneacetic acid (NAA) $2 \mathrm{mg} / \mathrm{L}$, kinetin (KIN) $2 \mathrm{mg} / \mathrm{L}$, $\mathrm{KIN} 2 \mathrm{mg} / \mathrm{L}+\mathrm{NAA} 2 \mathrm{mg} / \mathrm{L}$ and $\mathrm{KIN} 5 \mathrm{mg} / \mathrm{L}$ + indolebutyric acid (IAA) $5 \mathrm{mg} / \mathrm{L}$. The hybrid BAP $2 \mathrm{mg} / \mathrm{L}$ provided the greatest proliferation of shoots per explant per subculture and increasing multiplication rate up to the fourth subculture. BAP $2 \mathrm{mg} / \mathrm{L}$ + NAA $2 \mathrm{mg} / \mathrm{L}$ multiplied best the 'Smooth Cayenne'. Shoot proliferation practically did not occur up to the fourth subculture when KIN was used as cytokinin. The pineapple hybrid shoots from the fourth subculture in medium with BAP $2 \mathrm{mg} / \mathrm{L}$ and BAP $2 \mathrm{mg} / \mathrm{L}+\mathrm{NAA} 2 \mathrm{mg} / \mathrm{L}$ were put to root in MS medium with NAA $1 \mathrm{mg} / \mathrm{L}$, NAA $1 \mathrm{mg} / \mathrm{L}$ + KIN $2 \mathrm{mg} / \mathrm{L}, \mathrm{NAA} 0,5 \mathrm{mg} / \mathrm{L}+\mathrm{KIN} 2 \mathrm{mg} / \mathrm{L}, \mathrm{KIN} 2 \mathrm{mg} / \mathrm{L}$ and growth-regulatorfree medium. Shoots which multiplied in BAP had better rooting than those multiplied in NAA + BAP.
\end{abstract}

Index terms: Ananas comosus, in vitro culture, multiplication rate, growth regulators.

\section{Introdução}

A propagação do abacaxizeiro é predominantemente vegetativa e pode ser feita através de mudas que a planta emite. As técnicas utilizadas na propagação do abacaxizeiro são o enviveiramento do talo da planta, a destruição do meristema apical, que provoca a emissão de mudas do tipo rebentão, a transformação de flores em mudas mediante a pulverização da planta com produtos químicos na fase inicial de desenvolvimento da inflorescência e a propagação in vitro (Reinhardt, 1998).
A produção de mudas por cultura de tecidos permite obter milhares de mudas a partir de uma única gema em pequeno período de tempo e totalmente livres de problemas fitossanitários. Segundo Zepeda \& Sagawa (1981), a formação de gemas múltiplas a partir de gemas axilares de uma coroa, cultivadas in vitro, possibilitou a formação de 5.000 plântulas, num período de 12 meses. Dewald et al. (1988), trabalhando com multiplicação in vitro de diferentes cultivares de abacaxizeiro, verificaram uma grande variação no número de plantas obtidas ao final de 9 a 13 meses após o início da cultura. 
$\mathrm{Na}$ fase de estabelecimento das culturas in vitro, evidencia-se o comportamento do explante que se manifestará nas fases subsequientes da micropropagação. Alguns genótipos adaptam-se bem a diferentes composições de meio de cultura, enquanto outros requerem modificações para cada clone ou grupo de clones (Grattapaglia \& Machado, 1998). Segundo estes autores a adição de fitorreguladores supre as possíveis deficiências dos teores endógenos de hormônios nos explantes isolados da planta matriz.

A utilização de auxina e citocinina em protocolos de estabelecimento e de multiplicação de abacaxizeiro é citada por vários autores (Dewald et al., 1988; Fitchet, 1990; Hirimburegama \& Wijesinghe, 1992; Fitchet Purnell et al., 1993; Kiss et al., 1995; Escalona et al., 1999; Guerra et al., 1999). Estes autores usaram o meio MS para estabelecimento das culturas. Na maioria dos protocolos de multiplicação publicados para abacaxizeiro, a citocinina mais utilizada é benzilaminopurina (BAP), seguida de cinetina (CIN) (Fitchet, 1990; Hirimburegama \& Wijeshinghe, 1992; Kiss et al., 1995; Guerra et al., 1999).

Segundo Grattapaglia \& Machado (1998), a qualidade das hastes provenientes da fase de multiplicação determina, em geral, o sucesso do enraizamento, que pode ocorrer in vitro ou in vivo. Vários autores relatam o uso, na fase de enraizamento, do meio MS reduzido para 1/2,1/3 e 1/4 da sua concentração salina integral. Tipos e concentrações de auxinas são as variáveis que mais influem no enraizamento (Grattapaglia \& Machado, 1998), no entanto, Gupta (1986) refere-se à adição de citocinina como favorável ao enraizamento.

A necessidade de melhorar o estado fitossanitário de mudas de abacaxizeiro destinadas ao plantio e de multiplicar com eficiência e mais rapidamente genótipos de qualidade superior, disponibilizando maior quantidade de mudas em curto período, exige a otimização de protocolos de multiplicação in vitro.

O objetivo deste trabalho foi testar cinco combinações de fitorreguladores, baseadas em resultados de pesquisa publicados com micropropagação de abacaxizeiro, visando avaliar os efeitos na multiplicação in vitro do híbrido PExSC-52 do programa de melhoramento genético da Embrapa Mandioca e Fruticultura e da cultivar Smooth Cayenne.

\section{Material e Métodos}

O trabalho foi realizado no Laboratório de Fisiologia Vegetal da Universidade de Brasília, utilizando mudas do tipo filhote do abacaxizeiro híbrido PExSC-52 da
Embrapa Mandioca e Fruticultura, em Cruz das Almas, BA, e a cultivar Smooth Cayenne, proveniente de plantio comercial no Município de Monte Alegre, MG. O híbrido PExSC-52 foi desenvolvido pela Embrapa Mandioca e Fruticultura, sendo oriundo do cruzamento das cultivares Perolera x Smooth Cayenne.

As mudas, após a retirada das folhas de modo a deixar apenas a haste caulinar, foram lavadas em água corrente por quinze minutos e em seguida imersas em água com sabão líquido, contendo 2,4,4'-tricloro 2'-hidroxidifenil éter $0,5 \%$, por dez minutos e, logo após, lavadas em água destilada por três vezes. As gemas foram retiradas assepticamente em câmara de fluxo laminar, utilizando-se para desinfestação a imersão em álcool $70 \%$ por um minuto, hipoclorito de sódio a $1 \%$ por dez minutos e três lavagens em água estéril, e, a seguir, inoculadas em tubos de ensaio de $150 \times 25 \mathrm{~mm}$ contendo $15 \mathrm{~mL}$ de meio de cultura. As culturas foram mantidas em sala de incubação com intensidade luminosa de $50 \mu$ moles $\mathrm{m}^{2} \mathrm{~s}^{-1}$, temperatura de $25 \pm 3^{\circ} \mathrm{C}$ e fotoperíodo de 16 horas.

O delineamento experimental foi inteiramente casualizado, constituído de cinco tratamentos e 12 repetições, com os seguintes tratamentos: benzilaminopurina (BAP) $2 \mathrm{mg} / \mathrm{L}$; BAP $2 \mathrm{mg} / \mathrm{L}$ + ácido naftaleno acético (ANA) $2 \mathrm{mg} / \mathrm{L}$; cinetina (CIN) $2 \mathrm{mg} / \mathrm{L}$; CIN $2 \mathrm{mg} / \mathrm{L}+$ ANA $2 \mathrm{mg} / \mathrm{L}$; CIN $5 \mathrm{mg} / \mathrm{L}$ + ácido indol acético (AIA) $5 \mathrm{mg} / \mathrm{L}$. O meio de cultura básico usado foi o MS suplementado com mio-inositol $100 \mathrm{mg} / \mathrm{L}$, sacarose $30 \mathrm{~g} / \mathrm{L}$, ágar $7 \mathrm{~g} / \mathrm{L}$. $\mathrm{O} \mathrm{pH}$ foi ajustado para 5,8 antes da autoclavagem que foi realizada a $120^{\circ} \mathrm{C}$ por quinze minutos.

A taxa de multiplicação foi avaliada por cinco subculturas, partindo-se de 12 gemas axilares por tratamento. As subculturas foram feitas em intervalos de 45 dias. Os dados foram submetidos à análise de variância e as médias comparadas pelo teste de Duncan a 5\% de probabilidade. Brotos de abacaxizeiro híbrido produzidos in vitro, provenientes da quarta subcultura, em meio MS com BAP a $2 \mathrm{mg} / \mathrm{L}$ (brotações com 3,5 a $5,3 \mathrm{~cm}$ de altura) e em meio com BAP + ANA a $2 \mathrm{mg} / \mathrm{L}$ (brotações com 3,0 a 4,2 cm de altura) foram utilizados para teste de enraizamento in vitro.

Utilizou-se o delineamento experimental de parcela subdividida, constituído de dois tratamentos de multiplicação dos brotos (parcela maior) e cinco tratamentos inteiramente casualizados para enraizamento (parcela menor) com quatro repetições, e cinco brotos por repetição. Os tratamentos para enraizamento foram iguais em brotos provenientes de ambas as origens: ANA $1 \mathrm{mg} / \mathrm{L}$; 
ANA $1 \mathrm{mg} / \mathrm{L}$ + CIN $2 \mathrm{mg} / \mathrm{L}$; ANA 0,5 mg/L + CIN $2 \mathrm{mg} / \mathrm{L}$; $\mathrm{CIN} 2 \mathrm{mg} / \mathrm{L}$; sem regulador de crescimento, todos em meio básico MS.

Foram utilizados frascos de $300 \mathrm{~mL}$ contendo $40 \mathrm{~mL}$ de meio de cultura e um broto por frasco. As condições de incubação foram as mesmas utilizadas para a multiplicação. As avaliações foram realizadas aos trinta dias de cultivo. Os dados foram submetidos à análise de variância e as médias comparadas pelo teste de Duncan a 5\% de probabilidade.

\section{Resultados e Discussão}

Os genótipos micropropagados geraram diferentes números de explantes entre si e entre tratamentos, apesar de todos serem iniciados a partir de gemas axilares e terem recebido iguais condições de cultivo e manipulação entre e durante as subculturas, quando foram feitas as avaliações de taxa de multiplicação/genótipo/tra- tamento (Tabelas 1, 2 e 3). As diferenças encontradas nas taxas de multiplicação entre a cv. Smooth Cayenne e o híbrido PExSC-52 podem estar relacionadas às características dos abacaxizeiros Pérola e Smooth Cayenne acumuladas no híbrido PExSC-52, proporcionando superioridade de multiplicação desse genótipo em quase todos os tratamentos.

Diferentes clones oriundos da mesma cultivar, quando cultivados in vitro podem apresentar índices de variação na taxa de multiplicação. Essa variação, segundo Carneiro (1997), pode ser atribuída a mutações ocorridas naturalmente no genótipo, que ainda não se manifestaram no fenótipo e podem ser responsáveis por diferenças encontradas no desempenho das linhagens. Gemas axilares também podem não apresentar a mesma razão de multiplicação in vitro; enquanto algumas gemas apresentam maior e mais rápido potencial de multiplicação, outras têm multiplicação lenta (Grattapaglia \& Machado, 1998). Para os autores, esse

Tabela 1. Taxa de multiplicação, em cinco subculturas, do abacaxizeiro PExSC-52 e 'Smooth Cayenne'em meio MS com e sem reguladores de crescimento ${ }^{(1)}$.

\begin{tabular}{|c|c|c|c|c|c|c|}
\hline \multirow[t]{2}{*}{ Tratamentos } & \multicolumn{6}{|c|}{ Subcultura } \\
\hline & 1 & 2 & 3 & 4 & 5 & $\mathrm{CV}$ \\
\hline & \multicolumn{6}{|c|}{ PExSC-52 } \\
\hline BAP $2 \mathrm{mg} / \mathrm{L}$ & $3,6 \mathrm{aC}$ & $3,3 \mathrm{aC}$ & $7,5 \mathrm{aB}$ & $10,7 \mathrm{aA}$ & $6,9 \mathrm{aB}$ & 26,2 \\
\hline BAP $2 \mathrm{mg} / \mathrm{L}+\mathrm{ANA} 2 \mathrm{mg} / \mathrm{L}$ & $1,6 \mathrm{bC}$ & $1,5 \mathrm{bC}$ & $8,7 \mathrm{aA}$ & $9,6 \mathrm{aA}$ & $5,1 \mathrm{bB}$ & 20,6 \\
\hline $\mathrm{CIN} 2 \mathrm{mg} / \mathrm{L}$ & $1,2 \mathrm{bB}$ & $1,0 \mathrm{bB}$ & $1,3 \mathrm{bB}$ & $1,6 \mathrm{bB}$ & $2,4 \mathrm{cA}$ & 22,3 \\
\hline CIN 2 mg/L+ANA 2 mg/L & $1,2 \mathrm{bB}$ & $1,1 \mathrm{bB}$ & $2,2 \mathrm{bA}$ & $2,6 \mathrm{bA}$ & $2,8 \mathrm{cA}$ & 19,5 \\
\hline CIN $5 \mathrm{mg} / \mathrm{L}+\mathrm{AIA} 5 \mathrm{mg} / \mathrm{L}$ & $1,0 \mathrm{bB}$ & $1,1 \mathrm{bB}$ & $1,8 \mathrm{bAB}$ & $1,5 \mathrm{bAB}$ & $2,6 \mathrm{cA}$ & 23,1 \\
\hline \multirow[t]{2}{*}{$\mathrm{CV}(\%)$} & 22,3 & 19,5 & 23,2 & 20,1 & 18,4 & - \\
\hline & \multicolumn{6}{|c|}{ Smooth Cayenne } \\
\hline BAP $2 \mathrm{mg} / \mathrm{L}$ & $1,3 \mathrm{bB}$ & $1,5 \mathrm{aB}$ & $2,6 \mathrm{bB}$ & $5,3 \mathrm{aA}$ & $5,0 \mathrm{bA}$ & 17,5 \\
\hline BAP $2 \mathrm{mg} / \mathrm{L}+\mathrm{ANA} 2 \mathrm{mg} / \mathrm{L}$ & $2,8 \mathrm{aBC}$ & $1,6 \mathrm{aC}$ & $6,4 \mathrm{aA}$ & $3,8 \mathrm{abB}$ & $6,5 \mathrm{aA}$ & 16,7 \\
\hline CIN $2 \mathrm{mg} / \mathrm{L}$ & $1,3 \mathrm{bB}$ & $1,0 \mathrm{bB}$ & $1,0 \mathrm{cB}$ & $1,5 \mathrm{cA}$ & $1,4 \mathrm{cA}$ & 20,6 \\
\hline $\mathrm{CIN} 2 \mathrm{mg} / \mathrm{L}+\mathrm{ANA} 2 \mathrm{mg} / \mathrm{L}$ & $1,6 \mathrm{bB}$ & $1,0 \mathrm{bB}$ & $3,3 \mathrm{bA}$ & $2,3 \mathrm{bcAB}$ & $1,7 \mathrm{cB}$ & 23,3 \\
\hline CIN $5 \mathrm{mg} / \mathrm{L}+\mathrm{AIA} 5 \mathrm{mg} / \mathrm{L}$ & $1,1 \mathrm{bA}$ & $1,0 \mathrm{bA}$ & $1,1 \mathrm{cA}$ & $1,4 \mathrm{cA}$ & $1,3 \mathrm{cA}$ & 21,4 \\
\hline $\mathrm{CV}(\%)$ & 17,4 & 21,4 & 20,6 & 25,3 & 18,4 & - \\
\hline
\end{tabular}

Tabela 2. Taxa de multiplicação média em cinco subculturas do abacaxi PExSC-52 e 'Smooth Cayenne', em meio MS com reguladores de crescimento $^{(1)}$.

\begin{tabular}{lcc}
\hline Tratamentos & \multicolumn{2}{c}{ Taxa de multiplicação } \\
\cline { 2 - 3 } & PExSC-52 & Smooth Cayenne \\
\hline BAP 2 mg/L & $6,4 \mathrm{a}$ & $3,6 \mathrm{~b}$ \\
BAP 2 mg/L+ANA 2 mg/L & $5,3 \mathrm{~b}$ & $4,6 \mathrm{a}$ \\
CIN 2 mg/L & $1,4 \mathrm{c}$ & $1,2 \mathrm{~d}$ \\
CIN 2 mg/L+ANA 2 mg/L & $1,9 \mathrm{c}$ & $2,1 \mathrm{c}$ \\
CIN 5 mg/L+AIA 5 mg/L & $1,6 \mathrm{c}$ & $1,2 \mathrm{~d}$ \\
\hline CV $(\%)$ & 20,3 & 17,2 \\
\hline
\end{tabular}

(1) Médias seguidas pela mesma letra na coluna não diferem entre si (Duncan $\leq 0,05$ ).
Tabela 3. Explantes do abacaxi PExSC-52 produzidos em cada subcultura, nos diferentes tratamentos, tomando como base a taxa de multiplicação em cada subcultura, a partir de uma gema inoculada inicialmente.

\begin{tabular}{lrrrrr}
\hline Tratamentos & \multicolumn{5}{c}{ Total de explante/subcultura } \\
\cline { 2 - 6 } & 1 & \multicolumn{1}{c}{2} & \multicolumn{1}{c}{3} & \multicolumn{1}{c}{4} \\
\hline BAP $2 \mathrm{mg} / \mathrm{L}$ & 3,60 & 11,88 & 89,10 & 953,37 & $6.578,25$ \\
BAP $2 \mathrm{mg} / \mathrm{L}+$ ANA $2 \mathrm{mg} / \mathrm{L}$ & 1,60 & 2,40 & 20,88 & 200,45 & $1.022,28$ \\
CIN $2 \mathrm{mg} / \mathrm{L}$ & 1,20 & 1,20 & 1,56 & 2,50 & 5,99 \\
CIN 2 mg/L +ANA 2 mg/L & 1,20 & 1,32 & 2,90 & 7,55 & 21,14 \\
CIN 5 mg/L +AIA 5 mg/L & 1,00 & 1,10 & 1,98 & 2,97 & 7,72 \\
\hline
\end{tabular}


comportamento pode estar relacionado às características da planta-mãe, ou seja, ao seu genótipo e ao seu estado nutricional. Sendo assim, se gemas axilares que desde o início do cultivo in vitro apresentarem multiplicação insatisfatória e não forem incluídas no cálculo das médias, serão obtidos valores mais altos de taxa de multiplicação, independentemente do genótipo ou tratamento utilizado.

Na presença de BAP, o abacaxizeiro híbrido PExSC-52 mostrou taxas de multiplicação mais elevadas em relação à 'Smooth Cayenne' (Figura 1), tomando como base a média de cinco subculturas (Tabela 2). Diferentes taxas de multiplicação foram igualmente obtidas por
Dewald et al. (1988) para as cultivares Perolera, Smooth Cayenne e PR-1-67, utilizando meio de cultura com as mesmas concentrações de auxinas e citocininas (BAP 1,980 mg/L e ANA 2,008 mg/L). Os autores verificaram número médio de plantas 6,3 vezes maior para a cultivar PR-1-67 em relação a Smooth Cayenne. O número de plantas da cultivar Perolera foi inferior a PR-1-67 e 4,86 vezes superior ao da Smooth Cayenne. Resultados similares foram observados neste trabalho quanto ao comportamento do PExSC-52 e da 'Smooth Cayenne', quando submetidos a um mesmo protocolo, sugerindo diferenças genotípicas na resposta à indução morfogenética in vitro. A interação entre genótipos e

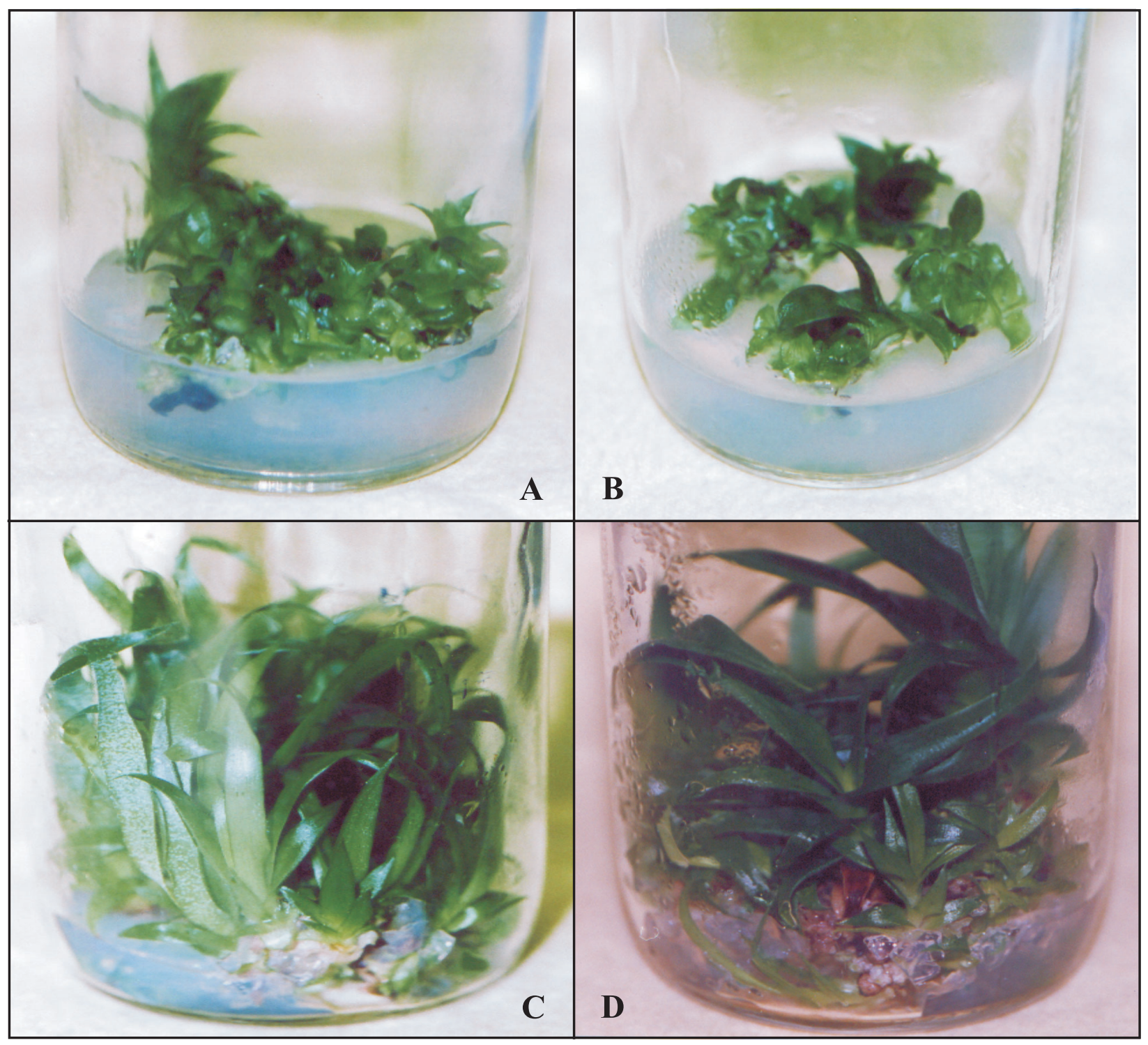

Figura 1. Brotos de abacaxizeiro multiplica dos em meio com BAP $2 \mathrm{mg} / \mathrm{L}$ provenientes da quarta subcultura. Aos 45 dias de cultivo - híbrido PExSC-52 (A) e cultivar Smooth Cayenne (B). Aos 75 de cultivo - PExSC52 (C) e Smooth Cayenne (D). 
fitorreguladores presentes no meio de cultura foi observada no híbrido e em 'Smooth Cayenne' que, ao final da quinta subcultura, apresentavam taxas de multiplicação de 6,4 e 3,6, respectivamente, quando se usou apenas o regulador de crescimento BAP a $2 \mathrm{mg} / \mathrm{L}$.

Ao se adicionar BAP + ANA, a cultivar Smooth Cayenne apresentou melhores resultados, enquanto o híbrido sofreu drástica redução na taxa de multiplicação (Figura 2), principalmente em relação à primeira e se- gunda subcultura (Tabelas 2 e 3). Variações na taxa de regeneração atribuídas a diferentes genótipos são citadas por Guerra et al. (1999) no cultivo in vitro das cultivares Perolera e Primavera, submetidas a um mesmo protocolo. A formação de aglomerados de gemas e minúsculos brotos, de 'Smooth Cayenne' em meio com BAP + ANA, dificultou a individualização dos brotos, no momento da repicagem, procedendo-se então, à divisão dos aglomerados, o que resultou em aumento no

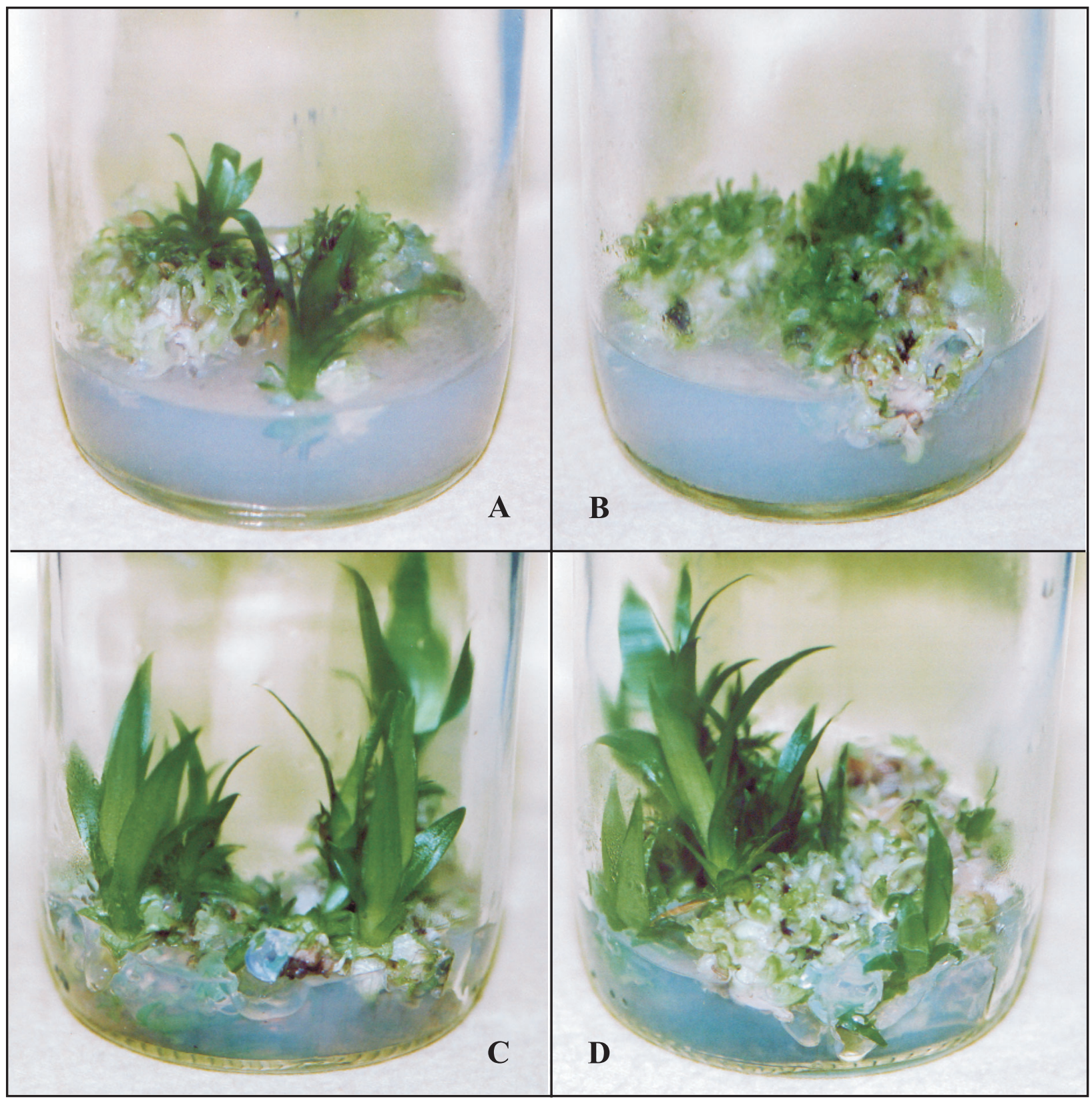

Figura 2. Brotos de abacaxizeiro multiplicados em meio com BAP $2 \mathrm{mg} / \mathrm{L}+$ ANA $2 \mathrm{mg} / \mathrm{L}$, provenientes da quarta subcultura. Aos 45 dias de cultivo - híbrido PExSC-52 (A) e cultivar Smooth Cayenne (B). Aos 75 dias de cultivo - PExSC-52 (C) e Smooth Cayenne (D). 
número de explantes/subcultura e, conseqüentemente, maior taxa de multiplicação (Tabela 1 e Figura 2B).

A combinação de ANA ou AIA a CIN não resultou em aumento substancial da taxa de multiplicação, sendo estes resultados semelhantes aos de Hirimburegama \& Wijeshinghe (1992), que conseguiram maior proliferação de gemas em meio de cultura contendo BAP a 2,25 mg/L do que com CIN a 2,15 mg/L.

A utilização de CIN isoladamente para a multiplicação de gemas proporcionou a formação de brotos bem definidos, tanto da 'Smooth Cayenne' quanto do híbrido. Contudo, as taxas de multiplicação foram bastante reduzidas, não justificando o uso da CIN na multiplicação desses materiais, nas concentrações utilizadas (Tabela 2).

Gemas axilares de abacaxizeiro 'Smooth Cayenne' e 'Queen' cultivadas em meio MS contendo CIN a $2 \mathrm{mg} / \mathrm{L}$ e zeatina a $2 \mathrm{mg} / \mathrm{L}$ produziram brotos bem definidos que eram facilmente isolados durante os subcultivos, enquanto BAP a $2 \mathrm{mg} / \mathrm{L}$ produziu brotos muito pequenos e indefinidos (Fitchet, 1990). Neste trabalho, os resultados diferiram dos obtidos por Fitchet (1990) com relação à formação de brotos em meio contendo BAP a $2 \mathrm{mg} / \mathrm{L}$. Brotos bem definidos no momento da repicagem foram facilmente individualizados (Figuras 1Ae 1B).

Brotações do abacaxizeiro PExSC-52 produzidas em presença de BAP e colocadas em meio com ANA a $1 \mathrm{mg} / \mathrm{L}$ isolado ou ANAa $0,5 \mathrm{mg} / \mathrm{L}$ combinado com CIN e sem fitorreguladores apresentaram-se $100 \%$ enraizadas, enquanto os brotos produzidos em BAP + ANA propiciaram porcentual de $100 \%$ de enraizamento apenas em meio sem reguladores de crescimento (Tabela 4).

Os níveis e a qualidade da auxina, em geral, são os fatores com maior influência no enraizamento, embora outros componentes do meio de cultura sejam freqüentemente alterados visando melhor promoção do enraizamento (Hu \& Wang, 1983). Diversas espécies, principalmente as herbáceas, enraízam facilmente in vitro sob baixos níveis de auxina ou, simplesmente, em meio

Tabela 4. Enraizamento de brotos de abacaxi PExSC 52 originados de dois tratamentos para multiplicação e cultivados em meio MS com e sem fitorreguladores.

\begin{tabular}{lcc}
\hline Tratamentos & \multicolumn{2}{c}{ Brotos enraizados $(\%)$} \\
\cline { 2 - 3 } & BAP & BAP + ANA \\
\hline ANA 1 mg/L & 100 & 75 \\
ANA $1 \mathrm{mg} / \mathrm{L}+\mathrm{CIN} 2 \mathrm{mg} / \mathrm{L}$ & 95 & 6 \\
ANA 0,5 mg/L+CIN 2 mg/L & 100 & 0 \\
CIN 2 mg/L & 15 & 12 \\
Sem fitorregulador & 100 & 100 \\
\hline
\end{tabular}

básico sem reguladores de crescimento (Anderson, 1984). Os resultados deste trabalho, cujos tratamentos sem reguladores de crescimento promoveram a rizogênese in vitro em $100 \%$ dos brotos de PExSC-52 produzidos em meio com BAP ou com BAP + ANA, corroboram tais informações.

Tipos diferentes de raízes foram observados nos brotos produzidos em meio com BAP, colocados em diferentes tratamentos para enraizamento. $\mathrm{Na}$ presença de ANA, isoladamente, o sistema radicular desenvolvido apresentou raízes de menor comprimento, mais uniformes e número de raízes secundárias bastante reduzido em relação ao formado em meio de cultura sem fitorregulador, com raízes finas, ramificadas e longas (Figura 3A e 3B, respectivamente e Tabela 5). Nos tratamentos com ANA a $1 \mathrm{mg} / \mathrm{L}+\mathrm{CIN}$ a $2 \mathrm{mg} / \mathrm{L}$, tinham comprimento variado e apresentavam-se mais enoveladas (Figura 3C). Em presença apenas de CIN praticamente não houve enraizamento (Figura 3D). Com a redução da concentração de ANA para $0,5 \mathrm{mg} / \mathrm{L}$, ocorreu a formação de raízes curtas, quebradiças e muito brancas (Figura 3E).

Alguns fatores podem ter contribuído para o bom enraizamento in vitro do híbrido PExSC-52, entre eles o tamanho das partes aéreas e a produção endógena de auxina pela planta. As partes aéreas são fontes de intensa produção de auxina que, ao ser translocada para a base, estimula a rizogênese (Barcelo Coll et al., 1988). A qualidade das partes aéreas provenientes da fase de multiplicação determina, em geral, o sucesso do enraizamento (Grattapaglia \& Machado, 1998). Segundo os autores, brotos pequenos não enraízam bem, necessitando de uma fase intermediária de alongamento.

Neste trabalho, os brotos colocados para enraizar, mesmo tendo igual período de cultivo, isto é, provenientes da quarta subcultura, eram maiores, mais bem formados, mostrando-se mais vigorosos quando multiplicados em BAP. Este estádio de desenvolvimento pode ter contribuído para o melhor enraizamento, em relação aos brotos produzidos em ANA + BAP, independentemente dos tratamentos para indução de rizogênese.

Durante a rizogênese, o crescimento acelerado das raízes pode retardar o desenvolvimento da parte aérea, porque o crescimento ativo do sistema radicular necessita de substâncias orgânicas translocadas da parte aérea para a base, comprometendo, assim, o desenvolvimento do caule e das folhas (Barcelo Coll et al., 1988). Uma vez estabelecida, a raiz tende a promover o crescimento da parte aérea (Cuzzuol et al., 1996). Embora o desenvolvimento dos sistemas caulinar e radicular tenda a um equilíbrio, em bromélias do gênero Tillandsia $\mathrm{o}$ 
crescimento do sistema caulinar é muito superior. Nessa bromélia, os caules produzem auxinas e citocininas desempenhando função dos dois sistemas em um só (Peres et al., 1997; Peres \& Kerbauy, 2000). Segundo os autores, muitas bromélias, como o próprio abacaxi, possuem estruturas caulinares capazes de absorver sais minerais.

O enraizamento in vitro de abacaxizeiro em meio MS sem hormônio foi utilizado por Zepeda \& Sagawa (1981) e Kiss et al. (1995), enquanto Fitchet (1990) utilizou re-

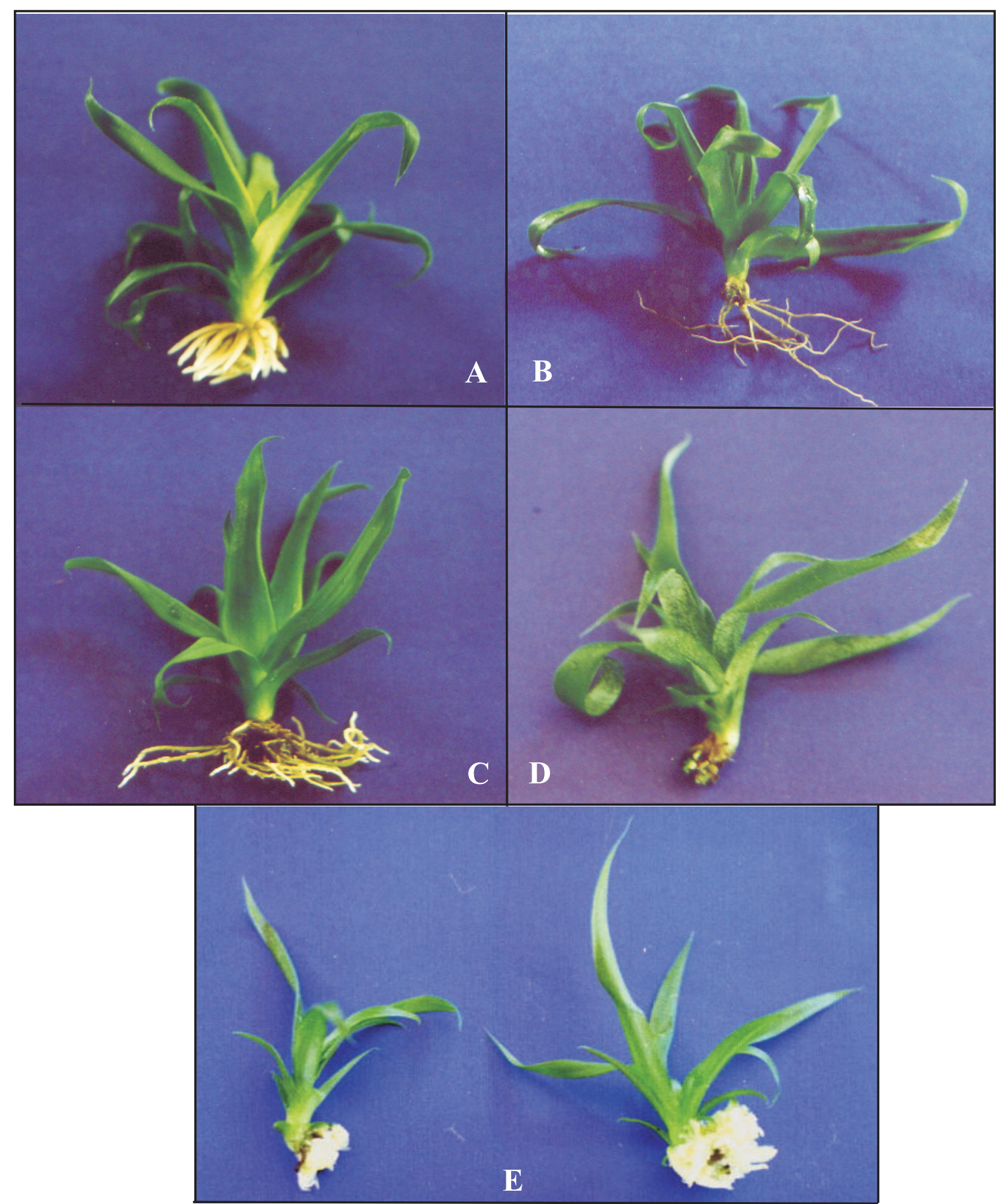

Figura 3. Brotos de abacaxi PExSC-52 multiplicados em meio com BAP $2 \mathrm{mg} / \mathrm{L}$ e enraizados em meio com ANA $1 \mathrm{mg} / \mathrm{L}$ (A); sem fitorregulador (B); ANA $1 \mathrm{mg} / \mathrm{L}+$ CIN $2 \mathrm{mg} / \mathrm{L}$ (C); CIN $2 \mathrm{mg} / \mathrm{L}$ (D) e ANA 0,5 mg/L + CIN $2 \mathrm{mg} / \mathrm{L}(\mathrm{E})$. 
Tabela 5. Efeito de diferentes tratamentos para enraizamento de brotos de abacaxi PExSC 52 multiplicados originalmente na presença de BAP $2 \mathrm{mg} / \mathrm{L}$ ou BAP $2 \mathrm{mg} / \mathrm{L}$ + ANA $2 \mathrm{mg} / \mathrm{L}$, aos 30 dias de cultivo.

\begin{tabular}{lccccc}
\hline \multirow{2}{*}{ Tratamentos } & \multicolumn{2}{c}{ Raízes/plântula } & & \multicolumn{2}{c}{ Altura da plântula (cm) } \\
\cline { 2 - 3 } \cline { 5 - 6 } & BAP & BAP + ANA & & BAP & BAP + ANA \\
\hline ANA 1 mg/L & $14,7 \mathrm{a}$ & $13,9 \mathrm{a}$ & & $6,6 \mathrm{a}$ & $4,7 \mathrm{a}$ \\
ANA 1 mg/L+CIN 2 mg/L & $8,6 \mathrm{~b}$ & $0,8 \mathrm{c}$ & & $5,0 \mathrm{bc}$ & $3,7 \mathrm{~b}$ \\
ANA 0,5 m/L+CIN 2 mg/L & $5,6 \mathrm{c}$ & $0,0 \mathrm{c}$ & & $5,6 \mathrm{~b}$ & $3,8 \mathrm{~b}$ \\
CIN 2 mg/L & $0,6 \mathrm{~d}$ & $0,4 \mathrm{c}$ & & $3,9 \mathrm{~d}$ & $3,7 \mathrm{~b}$ \\
Sem fitorregulador de crescimento & $5,4 \mathrm{c}$ & $2,7 \mathrm{~b}$ & & $4,5 \mathrm{c}$ & $4,7 \mathrm{a}$ \\
\hline Média & $7,0 \mathrm{~A}$ & $3,5 \mathrm{~B}$ & & $5,1 \mathrm{~A}$ & $4,1 \mathrm{~B}$ \\
CV $(\%)$ & 19,5 & 16,6 & & 21,3 & 20,2 \\
\hline
\end{tabular}

${ }^{(1)}$ Médias seguidas pela mesma letra na coluna não diferem entre si; letras maiúsculas representam separação de médias na linha (Duncan $\left.\leq 0,05\right)$; CV na linha $=18,7 \%$.

guladores de crescimento para induzir a formação de raízes in vitro. Eliminando a etapa de enraizamento in vitro, Ventura (1994) observou que o rendimento das brotações transferidas para aclimatação variou nas diferentes cultivares testadas, estimando uma taxa média de $50 \%$.

De acordo com Oliveira \& Cabral (1998), as plântulas de abacaxi produzidas in vitro devem ser levadas à aclimatação quando atingirem altura de $4 \mathrm{~cm}$. Estes autores recomendam que, no momento do transplantio das plântulas, as raízes mais longas devem ser cortadas, deixando-as com um comprimento máximo de $3 \mathrm{~cm}$. No protocolo para micropropagação do abacaxizeiro utilizado pela Universidade Federal de Lavras, Pasqual et al. (1998) não se referem ao enraizamento in vitro, mas recomendam uma fase de alongamento, entre multiplicação e aclimatização, em meio MS sem reguladores de crescimento.

O enraizamento in vitro sem o emprego de reguladores ou o enraizamento ex vitro, diretamente no substrato, é econômico e é uma prática desejável na automação da micropropagação. O sistema de enraizamento ex vitro, além de eliminar uma etapa in vitro, também beneficia a qualidade do sistema radicular desenvolvido, que é mais completo e funcional, com maior número de raízes secundárias, e com sistema vascular de conexão mais eficiente entre caule e raiz (Debergh \& Read, 1991), refletindo em melhor crescimento durante a fase de aclimatação.

Em algumas espécies herbáceas, o enraizamento pode ser realizado em condições ex vitro, diretamente no substrato. No entanto, pode apresentar alta taxa de mortalidade (Preece \& Sutter, 1991). O enraizamento de cravo (Dianthus caryophyllus L.) in vitro e ex vitro, feito por Cuzzuol et al. (1996), apresentou correlação significativa entre produção de matéria seca da raiz e da parte aérea, com as melhores taxas de crescimento recaindo para as formas de enraizamento in vitro, decorrente, provavelmente, do sistema radicular já existente na instalação do experimento. No enraizamento ex vitro, os autores também observaram efeito sinergístico no crescimento da parte aérea, embora menos acentuado, ante as necessidades energéticas da rizogênese ex vitro que devem ter sido satisfeitas pelas atividades fotossintéticas da parte aérea.

A avaliação em condição autotrófica do desempenho de plantas de abacaxi enraizadas in vitro e ex vitro, diretamente no substrato, é necessária na otimização de um protocolo de aclimatação.

\section{Conclusões}

1. A cultivar Smooth Cayenne e o híbrido PExSC-52 apresentam diferentes taxas de multiplicação como resposta a um mesmo protocolo, isto é, os efeitos dos tratamentos são genótipo dependentes.

2. Brotos multiplicados em presença de BAP a $2 \mathrm{mg} / \mathrm{L}$ apresentam melhor desempenho na rizogênese in vitro, independentemente da presença ou ausência de reguladores de crescimento no meio de cultivo.

\section{Referências}

ANDERSON, W.C. A revised tissue culture medium for shoot multiplication of Rhododendron. Journal of the American Society for Horticultural Science, v.109, p.343-347, 1984.

BARCELÓ COLL, J.; NICOLÁS RODRIGO, G.; SABATER GARCÍA, B.; SÁNCHEZ TÁMES, R. Fisiología vegetal. 6.ed. Madri: Pirámide, 1988. 662p.

CARNEIRO, I.F. Adequação de técnicas de cultura in vitro na obtenção de mudas de bananeira (Musa AAB) cultivar Maçã. 1997. 107p. Tese (Doutorado) - Universidade Federal de Goiás, Goiânia. 
CUZZUOL, G.R.F.; GALlO, L.A.; CROCOMO, O.J. Enraizamento de cravo (Dianthus caryophyllus L.) in vitro e ex vitro. Scientia Agricola, v.53, p.60-66, 1996.

DEBERGH, P.C.; READ, P.E. Micropropagation. In: DEBERGH, P.C.; ZIMMERMAN, R.H. (Ed.). Micropropagation: technology and application. Amsterdan: Kluwer Academic, 1991. p.1-13.

DEWALD, M.G.; MOORE, G.A.; SHERMAN, W.B.; EVANS, M.H. Production of pineapple plants in vitro. Plant Cell Reports, v.7, p.535-538, 1988.

ESCALONA, M.; LORENZO, J.C.; GONZÁLEZ, B.; DAQUINTA, M.; GONZÁLEZ, J.L.; DESJARDINS, Y.; BORROTO, C.G. Pineapple (Ananas comosus L. Merr.) micropropagation in temporary immersion systems. Plant Cell Reports, v.18, p.743-748, 1999.

FITCHET, M. Clonal propagation of Queen and Smooth Cayenne pineapples. Acta Horticulturae, n.275, p.261-266, 1990.

FITCHET PURNELL, M.; BARTHOLOMEW, D.P.; ROHRBACH, K.G. Maximum utilization of pineapple crowns for micropropagation. Acta Horticulturae, n.334, p.325-330, 1993.

GRATTAPAGLIA, D.; MACHADO, M.A. Micropropagação. In: TORRES, A.C.; CALDAS, L.S.; BUSO, J.A. (Ed.). Cultura de tecidos e transformação genética de plantas. Brasília: EmbrapaSPI; Embrapa-CNPH, 1998. v.1, p.183-260.

GUERRA, M.P.; DAL VESCO, L.L.; PESCADOR, R.; SCHUELTER, A.R.; NODARI, R.O. Estabelecimento de um protocolo regenerativo para a micropropagação do abacaxizeiro. Pesquisa Agropecuária Brasileira, v.34, p.1557-1563, 1999.

GUPTA, P.P. Eradication of mosaic disease and rapid clonal multiplication of bananas and plantains through meristem tip culture. Plant Cell, Tissue and Organ Culture, v.6, p.33-39, 1986.

HIRIMBUREGAMA, K.; WIJESINGHE, L.P.J. In vitro growth of Ananas comosus L. Merr. (pineapple) shoot apices on different media. Acta Horticulturae, n.319, p.203-208, 1992.
HU, C.Y.; WANG, P.J. Meristem, shoot tip and bud culture. In: EVANS, D.A.; SHARP, W.R.; AMMIRATO, P.V.; YAMADA, Y. Handbook of plant cell culture. New York: MacMillan, 1983. v.1, p.177-227.

KISS, E.; KISS, J.; GYULAI, G.; HESZKY, L.E. A novel method for rapid micropropagation of pineapple. HortScience, v.30, p.127129, 1995.

OLIVEIRA, R.P.; CABRAL, J.R.S. Protocolo para produção comercial de mudas de abacaxizeiro em laboratórios de cultura de tecidos. Cruz das Almas: Embrapa-CNPMF, 1998. 3p. (Biotecnologia em Foco).

PASQUAL, M.; MOREIRA, M.A.; ANJOS SOBRINHO, A. dos. Biotecnologia aplicada à produção de mudas de abacaxi. Informe Agropecuário, v.19, p.20-23, 1998.

PERES, L.E.P.; MERCIER, H.; KERBAUY, G.B.; ZAFFARI, G.R. Níveis endógenos de AIA, citocininas e ABA em uma orquídea acaule e uma bromélia sem raiz, determinado por HPLC e ELISA. Revista Brasileira de Fisiologia Vegetal, v.9, p.169-176, 1997.

PERES, L.E.P.; KERBAUY, G.B. Controle hormonal de desenvolvimento das raízes. Universa, v.8, p.181-196, 2000.

PREECE, J.E.; SUTTER, E.G. Aclimatization of micropropagated plants to the greenhouse and field. In: DEBERGH, P.C.; ZIMMERMAN, R.H. (Ed.). Micropropagation: technology and application. Amsterdan: Kluwer Academic, 1991. p.7-93.

REINHARDT, D.H.R.C. Manejo e produção de mudas de abacaxi. Informe Agropecuário, v.19, p.13-19, 1998.

VENTURA, J.A. Fusariose do abacaxizeiro: caracterização do patógeno, epidemiologia da doença, resistência e micropropagação do hospedeiro in vitro. 1994. 111p. Tese (Doutorado) - Universidade Federal de Viçosa, Viçosa.

ZEPEDA, C.; SAGAWA, Y. In vitro propagation of pineapple. HortScience, v.16, p.495, 1981.

Recebido em 11 de junho de 2003 e aprovado em 2 de junho de 2004 